\title{
Lung Disease in Rheumatoid Arthritis
}

\author{
Zulma X. Yunt, MD and Joshua J. Solomon, MD* \\ Autoimmune Lung Center, National Jewish Health, 1400 Jackson Street, Denver, CO 80205, \\ USA
}

\author{
Keywords \\ Rheumatoid arthritis; Extra-articular disease; Pulmonary; Interstitial lung disease; Interstitial \\ pneumonia; Bronchiolitis; Pleural effusion; Drug-induced lung disease
}

\section{INTRODUCTION}

Rheumatoid arthritis (RA) is a progressive, systemic autoimmune disorder characterized by articular and extra-articular manifestations. The lung is commonly a site of extra-articular disease. Within the lung, manifestations of RA vary and may include airways, parenchymal, vascular, and/or pleural disease (Box 1). Manifestations of lung disease in RA typically follow the development of articular disease, but in some instances lung involvement is the first manifestation of RA and is the most aggressive feature of the disease. ${ }^{1}$ Clinicians should therefore remain alert to the possibility of lung disease in all patients with RA.

\section{EPIDEMIOLOGY}

RA is the most common connective tissue disease (CTD), with a prevalence of $0.5 \%$ to $2 \%$ in the general population. ${ }^{2}$ The disease occurs more frequently in women than in men with a ratio of 3:1. Extra-articular disease occurs in approximately 50\% of patients, with the lung being a common site of involvement. ${ }^{3}$ Lung involvement may occur in as many as $67 \%$ of patients, although some reports indicate a lower incidence (around 10\%-20\%). ${ }^{4-6}$ This wide variation reflects differences in study design, study populations, and the way that lung disease in RA is defined. Many patients with RA have no clinical symptoms of respiratory disease despite radiographic or physiologic evidence of lung abnormalities, often leading to a misrepresentation of disease prevalence. In a study of 52 patients with RA, high-resolution computed tomography (HRCT) abnormalities were identified in $67.3 \%$ with only $40 \%$ of patients having respiratory symptoms. ${ }^{4}$ In addition to respiratory involvement from RA, medication toxicity and secondary pulmonary infections are important sources of lung disease that must be considered in patients with RA.

Mortality is increased in patients with RA with extra-articular manifestations relative to those without extra-articular involvement, with cardiovascular disease, infection, and lung

\footnotetext{
() 2015 Published by Elsevier Inc.

*Corresponding author. solomonj@njhealth.org.

Disclosure: NIH Diversity Supplement 3R01 HL109517-01A1S1.
} 
disease being the leading causes. Mortality in RA is greatest within the first 5 to 7 years after diagnosis and risk may be slightly higher in men than in women, with a mortality ratio of 2.07:1.97 respectively. ${ }^{7,8}$ Lung disease alone accounts for $10 \%$ to $20 \%$ of deaths in patients with RA, and most of these are attributed to interstitial lung disease (ILD) ${ }^{9-11}$

\section{FORMS OF LUNG DISEASE IN RHEUMATOID ARTHRITIS}

\section{Interstitial Lung Disease}

ILD refers to heterogeneous group of parenchymal lung disorders classified by distinct clinical, pathologic, and radiographic features. The 2013 American Thoracic Society/ European Respiratory Society official classification of the idiopathic interstitial pneumonias (IIPs) outlines the most recent histopathologic classifications of ILD, many of which may be seen in RA. ${ }^{12}$ The most common forms of ILD associated with RA are usual interstitial pneumonia (UIP) and nonspecific interstitial pneumonia (NSIP); however, organizing pneumonia (OP), desquamative interstitial pneumonia, lymphocytic interstitial pneumonia, diffuse alveolar damage, and acute interstitial pneumonia have been reported. ${ }^{13,14}$ Smoking, advanced age, high-titer anticyclic citrullinated peptide antibodies, high-titer rheumatoid factor, family history of RA, and in some studies male gender are all risk factors for developing RA-ILD. ${ }^{15}$

\section{Pathophysiology}

The pathophysiologic basis for development of ILD in patients with RA remains elusive. Available data suggest a role for both environmental and genetic factors. Specific human leukocyte antigen (HLA) variants including HLA-B54, HLA-DQB1*0601, HLA-B40, and HLA-DR4 have been associated with RA-ILD. ${ }^{16-19}$ Similarly, cigarette smoking has been linked with both RA and RA-ILD. ${ }^{20,21}$ Some speculate that the lungs may be a site of initial immune dysregulation that leads to the development of RA. ${ }^{22}$ Citrullinated proteins have been identified in bronchoalveolar lavage fluid from cigarette smokers without RA, and RArelated autoantibodies are detectable in the sputum of patients identified to be at risk for RA. ${ }^{23,24}$

It is hoped that investigations of biomarkers for RA-ILD will identify key molecules and thus provide more insight into disease immunopathogenesis and avenues for early diagnosis. To date, serum autoantibodies against multiple citrullinated proteins and peptides including fibrinogen, vimentin, and citrullinated isoforms of heat shock protein 90 and matrix metalloproteinase 1 (MMP-7) and interferon-gamma inducible protein $10^{25-27}$ have been associated with RA-ILD. The precise role of these proteins in tissue-specific disease manifestations is not known.

\section{Prognosis and mortality}

Information pertaining to the natural history of RA-ILD relies on data from a limited number of studies and more data are needed to confidently characterize prognosis and mortality within this population. The available studies indicate that patients with RA-ILD have a 3-fold increased risk of death relative to those without ILD. In addition, although overall mortality from RA seems to be decreasing, mortality from RA-ILD seems to be 
increasing, particularly in women and in older age groups. ${ }^{28,29}$ A study of 582 patients with RA identified a median survival of 2.6 years in those with ILD compared with 10 years in age-matched patients with RA without ILD. ${ }^{29}$ Within the category of RA-ILD, prognosis varies significantly depending on the precise histopathologic form of RA-ILD and from patient to patient. UIP is the most common subtype of RA-ILD and carries the worst prognosis, ${ }^{1,14,30}$ which differs from CTDs overall, in which the most common pattern of ILD is NSIP. ${ }^{1}$ High-quality studies of additional factors that influence prognosis are lacking. A recent systematic review of current literature investigating predictors of mortality in RAILD included 10 studies and found that male gender, older age, lower lung diffusion capacity for oxygen (DLCO), a finding of UIP, and the extent of fibrosis were significant predictors of mortality. ${ }^{31}$

\section{Clinical features}

Exertional dyspnea and cough of insidious onset are the predominant clinical symptoms of RA-ILD. Fatigue and generalized weakness are also frequently seen. Radio-graphic evidence of ILD on HRCT precedes the development of respiratory symptoms in a significant number of patients with RA and time to development of symptoms for patients with subclinical ILD is not known. Given the prevalence of lung involvement in RA, clinicians should have a low threshold to pursue evaluation of new respiratory complaints in this population. ${ }^{20}$ Once present, symptoms usually progress over time; however, the rate of progression is variable from patient to patient and within the different histopathologic forms of ILD. Studies indicate that patients with UIP may progress faster than other subtypes of ILD in RA and at rates similar to those reported for idiopathic pulmonary fibrosis (IPF). ${ }^{14,32}$

\section{Radiographic features}

HRCT has increased the diagnostic sensitivity and accuracy for RA-ILD greatly compared with chest radiograph alone. In a study of 150 consecutive individuals with RA, HRCT evidence of ILD was seen in 19\% of patients; however, bilateral inter-stitial infiltrates were seen on chest radiograph in less than $3 \%{ }^{6}$ The most common radiographic finding is a UIP pattern, which is characterized on HRCT by peripheral basilar predominant reticular abnormalities, honeycombing, traction bronchiectasis, and minimal to no ground-glass opacification (Fig. 1). NSIP is the other common pattern in RA-ILD and is characterized by reticulation and ground-glass with little or no architectural distortion or honeycombing (Fig. 2).

\section{Diagnostic evaluation}

Early symptoms of respiratory disease, particularly dyspnea on exertion, may be difficult to ascertain in patients with exercise-limiting joint disease. Clinicians should therefore remain alert to subtle symptoms, including new cough, change in activity level, or low resting oxygen levels. The initial diagnostic evaluation for patients with RA with respiratory symptoms includes an assessment of lung physiology with pulmonary function tests (PFTs), radiographic imaging with $\mathrm{HRCT}$, and assessment of the patient's oxygenation both at rest and with activity. Initial PFTs should include components of lung volume, airflow with bronchodilator challenge, and DLCO measurements. For initial imaging, HRCT imaging is recommended rather than chest radiograph for its superior sensitivity in detecting early 
parenchymal disease and small airways disease. ${ }^{6,33}$ Lung biopsy is not indicated in most cases of RA-ILD; however, if the diagnosis is uncertain or computed tomography findings are atypical, surgical lung biopsy may be useful. Transbronchial biopsies have low yield and are generally not performed, although they may be helpful for the purpose of ruling out drug-related disease or infection. For all patients with diffuse parenchymal disease, infection and drug-induced disease must be ruled out before making a diagnosis of ILD. Numerous medications used in the treatment of RA have reported pulmonary toxicities (Table 1).

\section{Treatment}

No randomized placebo-controlled therapeutic trials have been performed to date in RAILD. As such, no consensus therapeutic guidelines have been established. Our practice is to monitor these patients closely for progression of disease and initiate treatment when clinical symptoms manifest or when there is physiologic evidence of progressive disease. In all cases, risk of therapy must be weighed against threat of disease.

Current treatment regimens usually involve corticosteroid therapy with or without a cytotoxic agent; most commonly azathioprine, mycophenolate mofetil (MMF), or cyclophosphamide. Recent retrospective analyses centered on treatment of RA-ILD with MMF and rituximab have shown promising results. In a study of 125 patients with CTDrelated ILD treated with MMF, subgroup analysis of 18 patients with RAILD identified a trend toward improved forced vital capacity following initiation of therapy. ${ }^{34}$ Further, this drug has shown good patient tolerability and safety in patients with CTD-ILD. ${ }^{34,35}$ Retrospective studies with rituximab have recently shown success in cases of refractory CTD-ILD, ${ }^{36,37}$ although larger prospective studies are needed to validate these findings in patients with RA-ILD. Limited reports also exist for treatment with cyclosporine, methotrexate, and tumor necrosis factor (TNF) alpha inhibitors. ${ }^{36-41}$ Response to therapy in RA-ILD seems to correlate with histopathologic form of disease. As in IIPs, NSIP shows better response to therapy and prognosis than a UIP pattern. ${ }^{1,14}$ Note that control of joint disease does not translate to control of lung disease, and optimal management requires a coordinated approach between an experienced pulmonologist and rheumatologist.

All patients with RA-ILD should be encouraged to abstain from smoking. Smoking-related lung disease should be treated if present. Oxygenation should be evaluated during rest, ambulation, and sleep and supplemental oxygen should be prescribed as indicated. Vaccinations for influenza and pneumococcal pneumonia are recommended for all patients. We also recommend prophylaxis against Pneumocystis jiroveci pneumonia for all patients on immunosuppressive therapy. In managing the articular manifestations in patients with RA-ILD, methotrexate use should generally be avoided because of well-documented pulmonary toxicity. TNF-alpha inhibitors should be used with caution in these patients following reports of increased rates of lung toxicity with these agents. ${ }^{42,43}$ In spite of these reports, a prospective observational study of 367 patients with RA-ILD showed no increase in mortality following treatment with anti-TNF agents compared with standard immunomodulatory agents. ${ }^{44}$ Patients with progressive disease should be considered for lung transplant evaluation. Survival rates after transplant for RA-ILD are similar to those for IPF and with significant improvements in quality-of-life scores following transplantation. ${ }^{45}$ 


\section{Airways Involvement (Bronchiolitis, Bronchiectasis, and Cricoarytenoid Disease)}

Prevalence of airways disease in RA is high; it occurs in $39 \%$ to $60 \%$ of patients. ${ }^{46-48}$ Any part of the airway may be involved, including the large airways (upper and lower) and distal small airways. The most common manifestations are bronchiectasis, bronchiolitis, airway hyperreactivity, and cricoarytenoid arthritis. PFTs and HRCT obtained with expiratory images are useful in making a diagnosis of airways involvement with HRCT, showing greater sensitivity for detection of small airways disease relative to PFTs. ${ }^{34}$

Cricoarytenoid arthritis and bronchiectasis are the most common forms of large airway involvement. Cricoarytenoid abnormalities occur in as many as $75 \%$ of patients, although fewer have clinically significant symptoms. ${ }^{49}$ Arthritis of the cricoarytenoid joints leads to midline adduction of the vocal cords with resultant hoarseness and in some cases inspiratory stridor. Bronchiectasis, defined as destruction and widening of the large airways, occurs in $16 \%$ to $58 \%$ of patients with RA. ${ }^{50,51}$ Most cases are not clinically significant but, when present, symptoms include cough and sputum production. Treatment of these patients with a biologic agent has been reported as an independent risk factor for lower respiratory tract infection. 52

Small airways disease refers to disease involving the distal airways ( $2 \mathrm{~mm}$ in diameter or less). Two forms of small airways disease (follicular bronchiolitis and constrictive bronchiolitis) have been described in association with RA. Follicular bronchiolitis is identified pathologically by the presence of hyperplastic lymphoid follicles with reactive germ cell centers within bronchiole walls. Constrictive bronchiolitis (also referred to as obliterative bronchiolitis) is identified by concentric narrowing of membranous and respiratory bronchioles caused by peribronchiolar inflammation and fibrosis without evidence of lymphoid hyperplasia. ${ }^{53}$ There are limited reports regarding disease course and prognosis for RA-associated follicular and constrictive bronchiolitis. Prognosis is thought to be poor; however, in a recent prospective study in CTD-associated bronchiolitis (in which $50 \%$ of patients had RA), the forced expiratory volume in 1 second showed stability over time in both forms, suggesting that bronchiolitis associated with CTD may have a less aggressive course than idiopathic disease. ${ }^{54,55}$

\section{Rheumatoid Nodules}

Rheumatoid necrobiotic nodules are pulmonary lesions histologically composed of a central fibrinoid necrotic region surrounded by mononuclear cells, granulation tissue, lymphocytes, plasma cells, and fibroblasts. The nodules may be single or multiple and are typically found in pleural or subpleural regions, occasionally with cavitation. ${ }^{56,57}$ Rheumatoid nodules carry good prognosis and may come and go over time. Neoplasm and infection should be ruled out, but once a diagnosis is made no specific therapy is typically required.

\section{Vascular Disease}

Pulmonary arterial hypertension is exceedingly rare in RA. It is more commonly seen in other CTDs such as scleroderma and systemic lupus erythematosis. ${ }^{58}$ The most common form of vascular involvement in RA is rheumatoid vasculitis, which is characterized pathologically by the presence of a destructive inflammatory infiltrate within small and 
medium-sized blood vessel walls. This condition carries significant morbidity and mortality, but primary involvement of the lung is rare. ${ }^{59}$

\section{Pleural Involvement}

Pleuritis and pleural effusions are the most common forms of pleural disease in RA. RA effusions are exudative and sterile, often with low glucose (80\%) and low $\mathrm{pH}(71.4 \%) .{ }^{60} \mathrm{~A}$ cytologic finding of elongated macrophages and multinucleated giant cells alongside granulomatous debris is pathognomonic for rheumatoid effusions. ${ }^{61}$ These findings mirror those in rheumatoid synovitis or rheumatoid nodules. Occasionally, pleural involvement may precede joint disease. Pleural effusions often resolve spontaneously over time. As with rheumatoid lung nodules, infection and malignancy should be considered and ruled out, if appropriate.

\section{FUTURE CONSIDERATIONS/SUMMARY}

RA is a common disorder with a myriad of pulmonary manifestations. Although any compartment of the respiratory system is at risk, the ILDs cause the greatest concern. In its most severe form, affected patients can develop a fibrotic ILD with progression similar to that seen in IPF. Treatment is based on expert opinion and there are no placebo-controlled trials. In order to effectively care for these patients, a better understanding is needed of the link between synovitis and pulmonary disease. Predictors of lung involvement, biomarkers to clinically phenotype patients, and well-designed treatment trials are urgently needed.

\section{REFERENCES}

1. Lee HK, Kim DS, Yoo B, et al. Histopathologic pattern and clinical features of rheumatoid arthritisassociated interstitial lung disease. Chest. 2005; 127(6):2019-27. Key Reference. [PubMed: 15947315]

2. Gabriel SE, Crowson CS, Kremers HM, et al. Survival in rheumatoid arthritis: a population-based analysis of trends over 40 years. Arthritis Rheum. 2003; 48(1):54-8. [PubMed: 12528103]

3. Turesson C, O'Fallon WM, Crowson CS, et al. Occurrence of extraarticular disease manifestations is associated with excess mortality in a community based cohort of patients with rheumatoid arthritis. J Rheumatol. 2002; 29(1):62-7. [PubMed: 11824973]

4. Bilgici A, Ulusoy $\mathrm{H}$, Kuru O, et al. Pulmonary involvement in rheumatoid arthritis. Rheumatol Int. 2005; 25(6):429-35. [PubMed: 16133582]

5. Mori S, Cho I, Koga Y, et al. Comparison of pulmonary abnormalities on high-resolution computed tomography in patients with early versus longstanding rheumatoid arthritis. J Rheumatol. 2008; 35(8):1513-21. [PubMed: 18597412]

6. Dawson JK, Fewins HE, Desmond J, et al. Fibrosing alveolitis in patients with rheumatoid arthritis as assessed by high resolution computed tomography, chest radiography, and pulmonary function tests. Thorax. 2001; 56(8):622-7. [PubMed: 11462065]

7. Young A, Koduri G, Batley M, et al. Mortality in rheumatoid arthritis. Increased in the early course of disease, in ischaemic heart disease and in pulmonary fibrosis. Rheumatology (Oxford). 2007; 46(2):350-7. [PubMed: 16908509]

8. Thomas E, Symmons DP, Brewster DH, et al. National study of cause-specific mortality in rheumatoid arthritis, juvenile chronic arthritis, and other rheumatic conditions: a 20 year followup study. J Rheumatol. 2003; 30(5):958-65. [PubMed: 12734889]

9. Suzuki A, Ohosone Y, Obana M, et al. Cause of death in 81 autopsied patients with rheumatoid arthritis. J Rheumatol. 1994; 21(1):33-6. [PubMed: 8151583] 
10. Sihvonen S, Korpela M, Laippala P, et al. Death rates and causes of death in patients with rheumatoid arthritis: a population-based study. Scand J Rheumatol. 2004; 33(4):221-7. [PubMed: 15370716]

11. Turesson C, Jacobsson L, Bergstrom U. Extra-articular rheumatoid arthritis: prevalence and mortality. Rheumatology (Oxford). 1999; 38(7):668-74. [PubMed: 10461483]

12. Travis WD, Costabel U, Hansell DM, et al. An official American Thoracic Society/ European Respiratory Society statement: update of the international multidisciplinary classification of the idiopathic interstitial pneumonias. Am J Respir Crit Care Med. 2013; 188(6):733-48. [PubMed: 24032382]

13. Nakamura Y, Suda T, Kaida Y, et al. Rheumatoid lung disease: prognostic analysis of 54 biopsyproven cases. Respir Med. 2012; 106(8):1164-9. [PubMed: 22560113]

14. Kim EJ, Elicker BM, Maldonado F, et al. Usual interstitial pneumonia in rheumatoid arthritisassociated interstitial lung disease. Eur Respir J. 2010; 35(6):1322-8. Key Reference. [PubMed: 19996193]

15. Solomon JJ, Brown KK. Rheumatoid arthritis-associated interstitial lung disease. Open Access Rheumatol Res Rev. 2012; (4):21-31. Q13.

16. Charles PJ, Sweatman MC, Markwick JR, et al. HLA-B40: a marker for susceptibility to lung disease in rheumatoid arthritis. Dis Markers. 1991; 9(2):97-101. Key Reference. [PubMed: 1782749]

17. Scott TE, Wise RA, Hochberg MC, et al. HLA-DR4 and pulmonary dysfunction in rheumatoid arthritis. Am J Med. 1987; 82(4):765-71. Key Reference. [PubMed: 3494398]

18. Hillarby MC, McMahon MJ, Grennan DM, et al. HLA associations in subjects with rheumatoid arthritis and bronchiectasis but not with other pulmonary complications of rheumatoid disease. $\mathrm{Br}$ J Rheumatol. 1993; 32(9):794-7. Key Reference. [PubMed: 8369890]

19. Sugiyama Y, Ohno S, Kano S, et al. Diffuse panbronchiolitis and rheumatoid arthritis: a possible correlation with HLA-B54. Intern Med. 1994; 33(10):612-4. Key Reference. [PubMed: 7827377]

20. Gochuico BR, Avila NA, Chow CK, et al. Progressive preclinical interstitial lung disease in rheumatoid arthritis. Arch Intern Med. 2008; 168(2):159-66. Key Reference. [PubMed: 18227362]

21. Albano SA, Santana-Sahagun E, Weisman MH. Cigarette smoking and rheumatoid arthritis. Semin Arthritis Rheum. 2001; 31(3):146-59. [PubMed: 11740796]

22. Demoruelle MK, Deane KD, Holers VM. When and where does inflammation begin in rheumatoid arthritis? Curr Opin Rheumatol. 2014; 26(1):64-71. [PubMed: 24247116]

23. Makrygiannakis D, Hermansson M, Ulfgren AK, et al. Smoking increases peptidylarginine deiminase 2 enzyme expression in human lungs and increases citrulli-nation in BAL cells. Ann Rheum Dis. 2008; 67(10):1488-92. Key Reference. [PubMed: 18413445]

24. Willis VC, Demoruelle MK, Derber LA, et al. Sputum autoantibodies in patients with established rheumatoid arthritis and subjects at risk of future clinically apparent disease. Arthritis Rheum. 2013; 65(10):2545-54. [PubMed: 23817979]

25. Harlow L, Rosas IO, Gochuico BR, et al. Identification of citrullinated hsp90 iso-forms as novel autoantigens in rheumatoid arthritis-associated interstitial lung disease. Arthritis Rheum. 2013; 65(4):869-79. [PubMed: 23400887]

26. Giles JT, Danoff SK, Sokolove J, et al. Association of fine specificity and repertoire expansion of anticitrullinated peptide antibodies with rheumatoid arthritis associated interstitial lung disease. Ann Rheum Dis. 2014; 73(8):1487-94. [PubMed: 23716070]

27. Chen J, Doyle TJ, Liu Y, et al. Biomarkers of rheumatoid arthritis-associated inter-stitial lung disease. Arthritis Rheum. 2015; 67(1):28-38.

28. Olson AL, Swigris JJ, Sprunger DB, et al. Rheumatoid arthritis-interstitial lung disease-associated mortality. Am J Respir Crit Care Med. 2011; 183(3):372-8. [PubMed: 20851924]

29. Bongartz T, Nannini C, Medina-Velasquez YF, et al. Incidence and mortality of interstitial lung disease in rheumatoid arthritis: a population-based study. Arthritis Rheum. 2010; 62(6):1583-91. [PubMed: 20155830]

30. Solomon JJ, Ryu JH, Tazelaar HD, et al. Fibrosing interstitial pneumonia predicts survival in patients with rheumatoid arthritis-associated interstitial lung disease (RA-ILD). Respir Med. 2013; 107(8):1247-52. [PubMed: 23791462] 
31. Assayag D, Lubin M, Lee JS, et al. Predictors of mortality in rheumatoid arthritis-related interstitial lung disease. Respirology. 2014; 19(4):493-500. [PubMed: 24372981]

32. Park JH, Kim DS, Park IN, et al. Prognosis of fibrotic interstitial pneumonia: idiopathic versus collagen vascular disease-related subtypes. Am J Respir Crit Care Med. 2007; 175(7):705-11. [PubMed: 17218621]

33. Perez T, Remy-Jardin M, Cortet B. Airways involvement in rheumatoid arthritis: clinical, functional, and HRCT findings. Am J Respir Crit Care Med. 1998; 157(5 Pt 1):1658-65. Key Reference. [PubMed: 9603152]

34. Fischer A, Brown KK, Du Bois RM, et al. Mycophenolate mofetil improves lung function in connective tissue disease-associated interstitial lung disease. J Rheumatol. 2013; 40(5):640-6. [PubMed: 23457378]

35. Swigris JJ, Olson AL, Fischer A, et al. Mycophenolate mofetil is safe, well tolerated, and preserves lung function in patients with connective tissue disease-related interstitial lung disease. Chest. 2006; 130(1):30-6. [PubMed: 16840379]

36. Keir GJ, Maher TM, Ming D, et al. Rituximab in severe, treatment-refractory inter-stitial lung disease. Respirology. 2014; 19(3):353-9. [PubMed: 24286447]

37. Braun-Moscovici Y, Butbul-Aviel Y, Guralnik L, et al. Rituximab: rescue therapy in lifethreatening complications or refractory autoimmune diseases: a single center experience. Rheumatol Int. 2013; 33(6):1495-504. [PubMed: 23239037]

38. Chang HK, Park W, Ryu DS. Successful treatment of progressive rheumatoid interstitial lung disease with cyclosporine: a case report. J Korean Med Sci. 2002; 17(2):270-3. Key Reference. [PubMed: 11961317]

39. Puttick MP, Klinkhoff AV, Chalmers A, et al. Treatment of progressive rheumatoid interstitial lung disease with cyclosporine. J Rheumatol. 1995; 22(11):2163-5. [PubMed: 8596163]

40. Bargagli E, Galeazzi M, Rottoli P. Infliximab treatment in a patient with rheumatoid arthritis and pulmonary fibrosis. Eur Respir J. 2004; 24(4):708. [PubMed: 15459153]

41. Vassallo R, Matteson E, Thomas CF Jr. Clinical response of rheumatoid arthritis-associated pulmonary fibrosis to tumor necrosis factor-alpha inhibition. Chest. 2002; 122(3):1093-6. [PubMed: 12226061]

42. Lindsay K, Melsom R, Jacob BK, et al. Acute progression of interstitial lung disease: a complication of etanercept particularly in the presence of rheumatoid lung and methotrexate treatment. Rheumatology (Oxford). 2006; 45(8):1048-9. [PubMed: 16760195]

43. Ostor AJ, Crisp AJ, Somerville MF, et al. Fatal exacerbation of rheumatoid arthritis associated fibrosing alveolitis in patients given infliximab. BMJ. 2004; 329(7477):1266. [PubMed: 15564258]

44. Dixon WG, Hyrich KL, Watson KD, et al. Influence of anti-TNF therapy on mortality in patients with rheumatoid arthritis-associated interstitial lung disease: results from the British Society for Rheumatology Biologics Register. Ann Rheum Dis. 2010; 69(6):1086-91. [PubMed: 20444754]

45. Yazdani A, Singer LG, Strand V, et al. Survival and quality of life in rheumatoid arthritisassociated interstitial lung disease after lung transplantation. J Heart Lung Transplant. 2014; 33(5): 514-20. [PubMed: 24630861]

46. Geddes DM, Webley M, Emerson PA. Airways obstruction in rheumatoid arthritis. Ann Rheum Dis. 1979; 38(3):222-5. [PubMed: 485577]

47. Collins RL, Turner RA, Johnson AM, et al. Obstructive pulmonary disease in rheumatoid arthritis. Arthritis Rheum. 1976; 19(3):623-8. [PubMed: 1084751]

48. Hassan WU, Keaney NP, Holland CD, et al. Bronchial reactivity and airflow obstruction in rheumatoid arthritis. Ann Rheum Dis. 1994; 53(8):511-4. [PubMed: 7944635]

49. Brazeau-Lamontagne L, Charlin B, Levesque RY, et al. Cricoarytenoiditis: CT assessment in rheumatoid arthritis. Radiology. 1986; 158(2):463-6. [PubMed: 3941873]

50. Metafratzi ZM, Georgiadis AN, Ioannidou CV, et al. Pulmonary involvement in patients with early rheumatoid arthritis. Scand J Rheumatol. 2007; 36(5):338-44. [PubMed: 17963162]

51. Kochbati S, Boussema F, Ben Miled M, et al. Bronchiectasis in rheumatoid arthritis. High resolution computed pulmonary tomography. Tunis Med. 2003; 81(10):768-73. in French. [PubMed: 17722792] 
52. Geri G, Dadoun S, Bui T, et al. Risk of infections in bronchiectasis during disease-modifying treatment and biologics for rheumatic diseases. BMC Infect Dis. 2011; 11:304. [PubMed: 22046967]

53. Pipavath SJ, Lynch DA, Cool C, et al. Radiologic and pathologic features of bronchiolitis. AJR Am J Roentgenol. 2005; 185(2):354-63. [PubMed: 16037505]

54. Fernandez Perez ER, Krishnamoorthy M, Brown KK, et al. FEV1 over time in patients with connective tissue disease-related bronchiolitis. Respir Med. 2013; 107(6):883-9. [PubMed: 23582575]

55. Devouassoux G, Cottin V, Liote H, et al. Characterisation of severe obliterative bronchiolitis in rheumatoid arthritis. Eur Respir J. 2009; 33(5):1053-61. [PubMed: 19129282]

56. Anaya JM, Diethelm L, Ortiz LA, et al. Pulmonary involvement in rheumatoid arthritis. Semin Arthritis Rheum. 1995; 24(4):242-54. [PubMed: 7740304]

57. Walters MN, Ojeda VJ. Pleuropulmonary necrobiotic rheumatoid nodules. A review and clinicopathological study of six patients. Med J Aust. 1986; 144(12):648-51. [PubMed: 3713605]

58. Morikawa J, Kitamura K, Habuchi Y, et al. Pulmonary hypertension in a patient with rheumatoid arthritis. Chest. 1988; 93(4):876-8. [PubMed: 3349848]

59. Voskuyl AE, Hazes JM, Zwinderman AH, et al. Diagnostic strategy for the assessment of rheumatoid vasculitis. Ann Rheum Dis. 2003; 62(5):407-13. [PubMed: 12695150]

60. Avnon LS, Abu-Shakra M, Flusser D, et al. Pleural effusion associated with rheumatoid arthritis: what cell predominance to anticipate? Rheumatol Int. 2007; 27(10):919-25. [PubMed: 17294192]

61. Naylor B. The pathognomonic cytologic picture of rheumatoid pleuritis. The 1989 Maurice Goldblatt Cytology award lecture. Acta Cytol. 1990; 34(4):465-73. [PubMed: 2197838]

62. Kremer JM, Alarcon GS, Weinblatt ME, et al. Clinical, laboratory, radiographic, and histopathologic features of methotrexate-associated lung injury in patients with rheumatoid arthritis: a multicenter study with literature review. Arthritis Rheum. 1997; 40(10):1829-37. [PubMed: 9336418]

63. Walden PA, Mitchell-Weggs PF, Coppin C, et al. Pleurisy and methotrexate treatment. Br Med J. 1977; 2(6091):867. [PubMed: 200300]

64. Cannon GW, Ward JR, Clegg DO, et al. Acute lung disease associated with low-dose pulse methotrexate therapy in patients with rheumatoid arthritis. Arthritis Rheum. 1983; 26(10):126974. [PubMed: 6626285]

65. St Clair EW, Rice JR, Snyderman R. Pneumonitis complicating low-dose methotrexate therapy in rheumatoid arthritis. Arch Intern Med. 1985; 145(11):2035-8. [PubMed: 4062454]

66. Gispen JG, Alarcon GS, Johnson JJ, et al. Toxicity of methotrexate in rheumatoid arthritis. J Rheumatol. 1987; 14(1):74-9. [PubMed: 3572937]

67. Amital A, Shitrit D, Adir Y. The lung in rheumatoid arthritis. Presse Med. 2011; 40(1 Pt 2):e3148. [PubMed: 21196098]

68. Barrera P, Laan RF, van Riel PL, et al. Methotrexate-related pulmonary complications in rheumatoid arthritis. Ann Rheum Dis. 1994; 53(7):434-9. [PubMed: 7944614]

69. Toussirot E, Berthelot JM, Pertuiset E, et al. Pulmonary nodulosis and aseptic granulomatous lung disease occurring in patients with rheumatoid arthritis receiving tumor necrosis factor-alphablocking agent: a case series. J Rheumatol. 2009; 36(11):2421-7. [PubMed: 19797509]

70. Peno-Green L, Lluberas G, Kingsley T, et al. Lung injury linked to etanercept therapy. Chest. 2002; 122(5):1858-60. [PubMed: 12426295]

71. Dubey S, Kerrigan N, Mills K, et al. Bronchospasm associated with anti-TNF treatment. Clin Rheumatol. 2009; 28(8):989-92. [PubMed: 19340514]

72. Atzeni F, Boiardi L, Salli S, et al. Lung involvement and drug-induced lung disease in patients with rheumatoid arthritis. Expert Rev Clin Immunol. 2013; 9(7):649-57. [PubMed: 23899235]

73. Roubille C, Haraoui B. Interstitial lung diseases induced or exacerbated by DMARDS and biologic agents in rheumatoid arthritis: a systematic literature review. Semin Arthritis Rheum. 2014; 43(5): 613-26. [PubMed: 24231065]

74. Sakai F, Noma S, Kurihara Y, et al. Leflunomide-related lung injury in patients with rheumatoid arthritis: imaging features. Mod Rheumatol. 2005; 15(3):173-9. [PubMed: 17029058] 
75. Suissa S, Hudson M, Ernst P. Leflunomide use and the risk of interstitial lung disease in rheumatoid arthritis. Arthritis Rheum. 2006; 54(5):1435-9. [PubMed: 16645972]

76. Liote H, Liote F, Seroussi B, et al. Rituximab-induced lung disease: a systematic literature review. Eur Respir J. 2010; 35(3):681-7. [PubMed: 19608586]

77. Parry SD, Barbatzas C, Peel ET, et al. Sulphasalazine and lung toxicity. Eur Respir J. 2002; 19(4): 756-64. [PubMed: 11999006]

78. Hamadeh MA, Atkinson J, Smith LJ. Sulfasalazine-induced pulmonary disease. Chest. 1992; 101(4):1033-7. [PubMed: 1348220]

79. Ikegawa K, Hanaoka M, Ushiki A, et al. A case of organizing pneumonia induced by tocilizumab. Intern Med. 2011; 50(19):2191-3. [PubMed: 21963739]

80. Kawashiri SY, Kawakami A, Sakamoto N, et al. A fatal case of acute exacerbation of interstitial lung disease in a patient with rheumatoid arthritis during treatment with tocilizumab. Rheumatol Int. 2012; 32(12):4023-6. [PubMed: 20480164]

81. Nishimoto N, Yoshizaki K, Miyasaka N, et al. Treatment of rheumatoid arthritis with humanized anti-interleukin- 6 receptor antibody: a multicenter, double-blind, placebo-controlled trial. Arthritis Rheum. 2004; 50(6):1761-9. [PubMed: 15188351] 


\section{Box 1 Pulmonary manifestation of RA}

Interstitial lung disease

- Usual interstitial pneumonia

- Nonspecific interstitial pneumonia

- Organizing pneumonia

- Lymphocytic interstitial pneumonia

- Acute interstitial pneumonia

Airways disease

- Follicular bronchiolitis

- Constrictive bronchiolitis (obliterative bronchiolitis)

- Bronchiectasis

- Cricoarytenoid arthritis

Rheumatoid nodules

Pleural disease

- Pleuritis

- Pleural effusion

- Pneumothorax

- Empyema

Vascular disease

- Pulmonary hypertension

- Vasculitis

Rheumatoid pneumoconiosis (Caplan syndrome)

Drug toxicity

Infection

Amyloidosis

Fibrobullous disease 


\section{KEY POINTS}

- Rheumatoid arthritis commonly affects the lungs and can involve any compartment of the respiratory system.

- Usual interstitial pneumonia and nonspecific interstitial pneumonia are the most common patterns seen with interstitial involvement in rheumatoid arthritis.

- Treatment consists of long-term therapy with immunomodulatory agents.

- Further studies are needed to better characterize patients, predict progression, and deter mine optimal therapeutic regimens. 


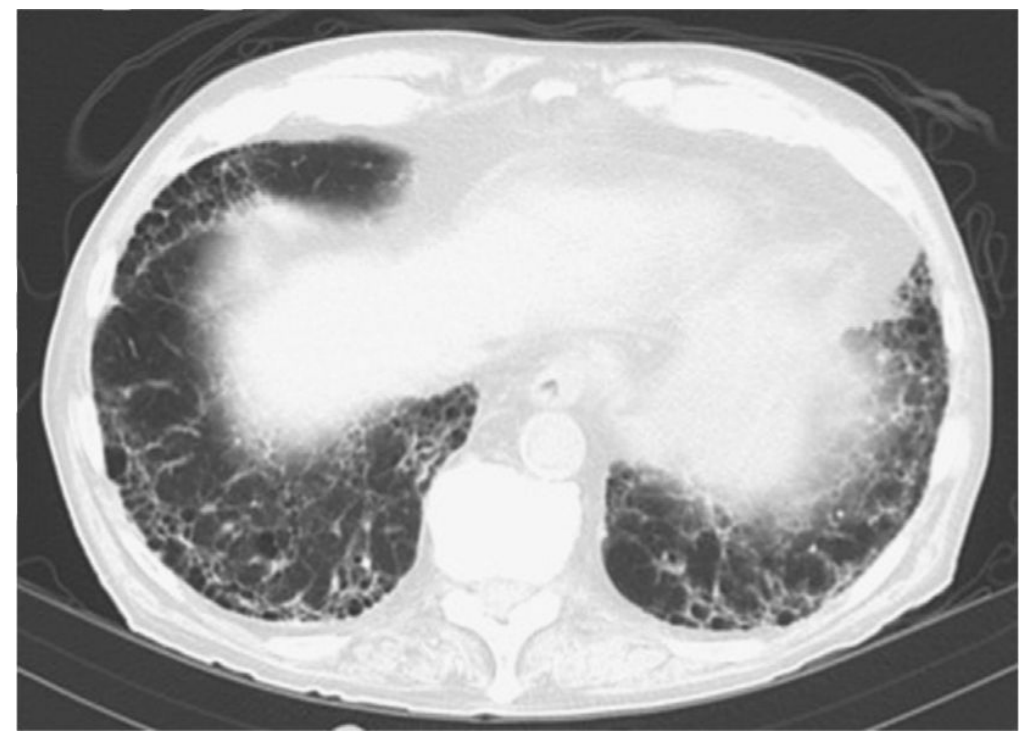

Fig. 1.

UIP in RA. The UIP pattern consists of peripheral basilar predominant reticular abnormalities, honeycombing, traction bronchiectasis, and minimal to no ground-glass opacification. 


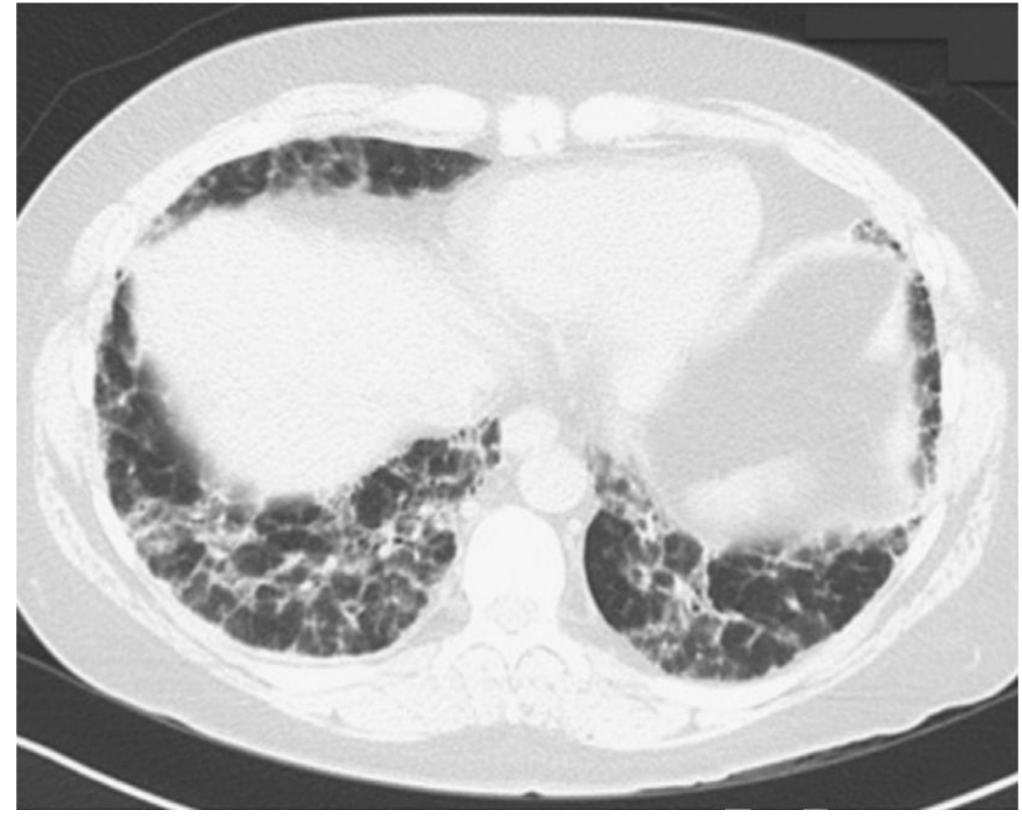

Fig. 2.

Nonspecific interstitial pneumonia in RA. The nonspecific interstitial pneumonia pattern consists of reticulation and ground-glass with little or no architectural distortion or honeycombing. 


\section{Table 1}

\section{Lung toxicity of rheumatoid therapies}

\begin{tabular}{|c|c|c|c|}
\hline Medication & Symptoms & Radiopathologic Findings & Incidence \\
\hline Methotrexate & Dyspnea, cough, fever ${ }^{62}$ & $\begin{array}{l}\text { Common: bilateral interstitial granulomatous infiltrates with } \\
\text { ground-glass opacification on chest } \mathrm{CT}^{62} \\
\text { Uncommon: unilateral infiltrates, pleural effusions, } \\
\text { reticulonodular disease, hilar lymphadenopathy }{ }^{63-}\end{array}$ & $\begin{array}{l}0.3 \%-11.6 \% \\
\text { Most cases occur within } 2 \text { y of } \\
\text { drug initiation and may occur after } \\
\text { a single dose }\end{array}$ \\
\hline Anti-TNF & Dyspnea & $\begin{array}{l}\text { Aseptic granulomatous pulmonary nodules, both } \\
\text { noncaseating and necrotizing } 69,70 \\
\text { Accelerated interstitial lung infiltrates } \\
\text { Bronchospasm }\end{array}$ & ILD, $0.5 \%-3 \% 72$ \\
\hline Leflunomide & Dyspnea, fever, cough $^{73}$ & $\begin{array}{l}\text { Diffuse or patchy ground-glass opacities. Often with septal } \\
\text { thickening } 74\end{array}$ & $\begin{array}{l}\text { ILD, }<1 \% 73 \\
\text { 2-fold increased risk of new ILD } \\
\text { seen in those with prior } \\
\text { methotrexate use }\end{array}$ \\
\hline Rituximab & Dyspnea & $\begin{array}{l}\text { Acute/subacute } \mathrm{OP}^{76} \\
\text { Acute respiratory distress syndrome }\end{array}$ & Unknown \\
\hline Sulfasalazine & Dyspnea, cough & $\begin{array}{l}\text { Variable. Most commonly, eosinophilic pneumonia and } \\
\text { peripheral eosinophilia } \\
\text { Interstitial fibrosis }^{78}\end{array}$ & Unknown \\
\hline Tocilizumab & - & $\begin{array}{l}\mathrm{OP}^{79} \\
\text { Exacerbation of } \mathrm{ILD}^{80} \\
\text { Allergic pneumonitis }\end{array}$ & Unknown \\
\hline
\end{tabular}

Abbreviations: CT, computed tomography; TNF, tumor necrosis factor. 